\title{
Cloning, preparation and characterization of biologically active recombinant caprine placental lactogen
}

\author{
E Sakal ${ }^{1}$, C Bignon ${ }^{2}$, N Chapnik-Cohen ${ }^{1}$, N Daniel ${ }^{2}$, J Paly ${ }^{2}$, \\ L Belair ${ }^{2}$, J Djiane ${ }^{2}$ and A Gertler ${ }^{1}$
}

${ }^{1}$ Institute of Biochemistry, Food Science and Nutrition, Faculty of Agricultural, Food and Environmental Quality Sciences, The Hebrew University of Jerusalem, Rehovot 76100, Israel and ${ }^{2}$ Unité d’Endocrinologie Moléculaire, Institut National de la Recherche Agronomique, 78352 Jouy-en-Josas Cedex, France

(Requests for offprints should be addressed to A Gertler)

\begin{abstract}
Caprine placental lactogen (cPL) cDNA was cloned by reverse transcription (RT)-PCR from total RNA of goat placenta. The PCR product encoding for the mature protein was gel purified, ligated to pGEM-T and finally subcloned into a pET8c prokaryotic expression vector. E. coli cells (BL-21) transformed with this vector overexpressed large amounts of cPL upon induction with Isopropyl-1-thio- $\beta$-D-galactopyranoside. The expressed protein, found in the inclusion bodies, was refolded and purified to homogeneity on Q-Sepharose and SPSepharose columns, yielding two electrophoretically pure fractions (cPL-Q and cPL-S), composed of over 98\% of monomeric protein of the expected molecular mass of $\sim 23 \mathrm{kDa}$. Binding of $\mathrm{cPL}$ to the extracellular domain
\end{abstract}

(ECD) of prolactin receptors (PRLR) from rat (r), rabbit $(\mathrm{rb})$, and bovine (b), growth hormone receptors (GHR) from human (h) and rabbit, and binding to rabbit mammary gland membranes revealed similar binding profiles for cPL-Q, cPL-S and ovine (o)PL. Caprine PL was capable of forming 1:2 complexes with hGHR-ECD, rbGHR-ECD, rPRLR-ECD and rbPRLR-ECD whereas with bPRLRECD only a 1:1 complex was detected. The biological activity of both cPL fractions resulting from proper renaturation was further evidenced by their ability to stimulate proliferation of $\mathrm{Nb}_{2}$ cells, FDC-P1 cells transfected with rabbit or human GHRs and by stimulation of $\beta$-casein synthesis in rabbit and ovine mammary gland acini cultures. Journal of Endocrinology (1998) 159, 509-518

\section{Introduction}

Placental lactogens (PLs) are secreted from placentae of primates, rodents and ruminants into the maternal and fetal circulations. Those polypeptide hormones, sharing various degrees of homology, are structurally related to the growth hormone $(\mathrm{GH})$ /prolactin $(\mathrm{PRL}) /$ cytokine family of hormones (Wallis 1992). They are usually $22-23 \mathrm{kDa}$ proteins, and some of them are glycosylated yielding higher molecular masses (Forsyth 1986). All members of this family exhibit a similar mechanism of action and receptor activation via homo- or heterodimerization of the receptor extracellular domain and subsequent transphosphorylation of receptor-associated JAK2 or other related kinases (Goffin \& Kelly 1997).

Although the specific biological functions of PLs are not understood, they probably have multiple biological effects, similar to GH and PRL. The level of PL in maternal and fetal blood is highly species dependent, e.g. the concentration in ewes is relatively high, whereas in cows it is very low (Byatt et al. 1987). It has been suggested that PL may function as a unique fetal growth hormone, based on findings that the ovine (o) fetus responds to oPL. This response includes stimulation of glycogen synthesis, amino acid transport, cellular proliferation and insulin-like growth factor (IGF-I) synthesis. These biological effects in the fetus are only slightly, or not at all, affected by ovine or human (h) GHs or oPRL, suggesting that oPL may have specific effects (for review see Anthony et al. 1995). We have found that bovine (b) PL and oPL are capable of acting through prolactin receptors (PRLRs) in bovine (Shamay et al. 1990) and ovine (Sakal et al. 1997) mammary glands as well as in the rat $\mathrm{Nb}_{2}$ lymphoma cell line (Byatt et al. 1990, Sakal et al. 1997). We have also shown by binding experiments that unique bovine placental lactogen receptors (PLRs) are present in the endometrium of pregnant cows (Galosi et al. 1991). Thus, bPL and most likely also oPL (Anthony et al. 1995) are unusual in that they are capable of recognizing and subsequently exhibiting their biological activity through three different types of receptors: (i) specific PLRs which it has been suggested exist mainly in fetal tissues (Freemark \& Comer 1989), (ii) growth hormone receptors (GHRs) and (iii) PRLRs.

Caprine placental lactogen (cPL), similar to oPL, was increased during pregnancy, and its level during weeks 16-20 of pregnancy correlated with postpartum milk yield (Forsyth 1986). The endocrine profile during caprine 
pregnancy is different from that of the ovine; while in the latter the placenta becomes the primary source of progesterone in the second and the third trimesters of pregnancy, in the caprine the corpus luteum alone is responsible for progesterone production throughout the whole pregnancy (Hulet \& Shelton 1980). The role of cPL in controlling this process has not yet been clarified. Caprine milk is gaining growing attention as a substitute for bovine milk, mainly in the cases of allergy syndromes or for adults lacking lactase. As cPL has not been cloned before, the present work was aimed at cloning and preparing substantial quantities of recombinant $\mathrm{cPL}$ that will facilitate studies in the homologous species. In order to clone cPL we used the known sequence of oPL and have found that cPL shows $85 \%$ homology to oPL. It enabled us to clone, express and purify CPL to homogeneity and thus to compare its biological activity with that of oPL, which we have studied before (Sakal et al. 1997).

\section{Materials and Methods}

\section{Materials}

Recombinant hGH was obtained from Biotechnology General Inc. (Ness-Zioma, Israel). Recombinant nonglycosylated rabbit (rb), rat (r) and bovine (b) PRLR extracellular domains (ECDs), hGHR-ECD and oPL were prepared as described previously (Bignon et al. 1994, Sandowski et al. 1995, Tchelet et al. 1995, Sakal et al. 1997). Rabbit GHR-ECD was also prepared in our laboratory and its preparation will be described elsewhere. Ovine prolactin (NIDKK AFP-8277E) was obtained from the National Hormone and Pituitary Program (Bethesda, MD, USA). Carrier-free $\mathrm{Na}\left[{ }^{125} \mathrm{I}\right]$ was purchased from the New England Nuclear Corp. (Boston, MA, USA). Isopropyl-1-thio- $\beta$-D-galactopyranoside (IPTG), RPMI1640 medium, lysozyme, Triton X-100 and bovine serum albumin (BSA, RIA grade) were obtained from Sigma Chemical Co. (St Louis, MO, USA). Superdex 75 HR 10/30 column, Q-Sepharose and SP-Sepharose (fast flow) were purchased from Pharmacia LKB Biotechnology AB (Uppsala, Sweden). SDS-PAGE reagents were purchased from BioRad Laboratories (Richmond, CA, USA).

\section{Cloning of $c P L c D N A$}

The cPL cDNA was cloned by reverse transcription (RT)-PCR. One microgram total RNA from goat placenta was reverse transcribed, and a fraction of the reaction was PCR-amplified with Hi-Taq polymerase (Bioprobe Systems SA, Montreuil, France), between primers cPL5' (GGA TTT CTC TCC AAT CCT CAT G) and cPL3' (ATA AAA CTC AAA GAA GCT TTT GAC), deduced from the ovine PL sequence (Colosi et al. 1989) in the following program: $\left(94{ }^{\circ} \mathrm{C}\right.$ for $\left.6 \mathrm{~min}\right) \times 1,\left(94^{\circ} \mathrm{C}\right.$ for $1 \mathrm{~min}, 50{ }^{\circ} \mathrm{C}$ for $30 \mathrm{~s}, 72{ }^{\circ} \mathrm{C}$ for $\left.1 \mathrm{~min}\right) \times 20,\left(72{ }^{\circ} \mathrm{C}\right.$ for $10 \mathrm{~min}) \times 1$. The PCR product was gel purified and, after extraction, ligated to pGEM-T vector (Promega, Madison, WI, USA). Six white colonies were screened by PCR with universal M13 sequencing primers for the presence of insert, and the first four were sequenced.

\section{Subcloning of $c P L c D N A$ into $p E T 8 c$ expression vector}

To facilitate the expression of the unfused protein in a prokaryotic expression vector, the signal sequence was removed from the cPL cDNA and restriction sites and a new translation start was added. The cPL cDNA (clone 4) was used as template in a PCR experiment with primers cPL3 (GAT ATC GAA TTC CCA TGG AGA ACT ATC CAC CAT AC) and cPL4 (AAG CTT CTG CAG GGA TCC TTA GCA TGA GGT CAA TCG GCA), and $P f u$ DNA polymerase (Stratagene Ltd, Cambridge, $\mathrm{UK})$ in the following program: $\left(94^{\circ} \mathrm{C}\right.$ for $\left.5 \mathrm{~min}\right) \times 1$, $\left(94{ }^{\circ} \mathrm{C}\right.$ for $1 \mathrm{~min}, 55^{\circ} \mathrm{C}$ for $30 \mathrm{~s}, 75^{\circ} \mathrm{C}$ for $\left.2 \mathrm{~min}\right) \times 15$, $\left(75^{\circ} \mathrm{C}\right.$ for $\left.15 \mathrm{~min}\right) \times 1$. The PCR product was separated from the template by gel electrophoresis and, after digestion by EcoRI and BamHI, subcloned into EcoRI/BamHIdigested pBluescript. After sequencing, the insert from one colony was subcloned from pBluescript into pET8c predigested with NcoI/BamHI. Automatic DNA sequencing was performed to confirm the proper sequence.

\section{Expression, refolding and purification of $c P L$}

Transformed E. coli BL21 cells were grown in Terrific Broth medium to $\mathrm{OD}_{600}=0.9$ and IPTG was added to a final concentration of $0.4 \mathrm{mM}$. Cells were grown for an additional period of 4 to $6 \mathrm{~h}$, and then harvested by $10 \mathrm{~min}$ centrifugation at $6000 \mathrm{~g}$ and frozen. Over $95 \%$ of the cPL protein was found in the inclusion bodies which were prepared according to the previously described protocol (Gertler et al. 1992). The inclusion body pellet obtained from 2.51 fermentation culture was solubilized in $600 \mathrm{ml}$ $4.5 \mathrm{M}$ urea buffered with $40 \mathrm{mM}$ Tris base. The $\mathrm{pH}$ was increased to 11.3 with $\mathrm{NaOH}$, cysteine was added to $0 \cdot 1 \mathrm{mM}$, and the clear solution was stirred at $4{ }^{\circ} \mathrm{C}$ for $1 \mathrm{~h}$. It was then diluted with two volumes of water and dialyzed for $48 \mathrm{~h}$ against $4 \times 10110 \mathrm{mM}$ Tris-HCl, $\mathrm{pH}$ 9.0. The resultant solution was loaded at $120 \mathrm{ml} / \mathrm{h}$ onto a Q-Sepharose column $(2 \cdot 6 \times 7 \mathrm{~cm})$, pre-equilibrated with $10 \mathrm{mM}$ Tris- $\mathrm{HCl}, \mathrm{pH} 9.0$ at $4{ }^{\circ} \mathrm{C}$. Elution was carried out using a discontinuous $\mathrm{NaCl}$ gradient in the same buffer at a rate of $120 \mathrm{ml} / \mathrm{h}$, and $10 \mathrm{ml}$ fractions were collected. Protein concentration was determined by absorbance at $280 \mathrm{~nm}$, and monomer content by gel-filtration chromatography on a Superdex 75 HR 10/30 column. The monomeric cPL was designated cPL-Q. As cPL was only partially absorbed to Q-Sepharose, the unabsorbed solution was brought to $\mathrm{pH} 5 \cdot 0$ with $10 \% \mathrm{HAc}$ and reloaded on SP-Sepahrose column $(1.6 \times 8 \mathrm{~cm})$ pre-equilibrated with $25 \mathrm{mM} \mathrm{NaAc}, \mathrm{pH} 5 \cdot 0$ at $4{ }^{\circ} \mathrm{C}$. The 


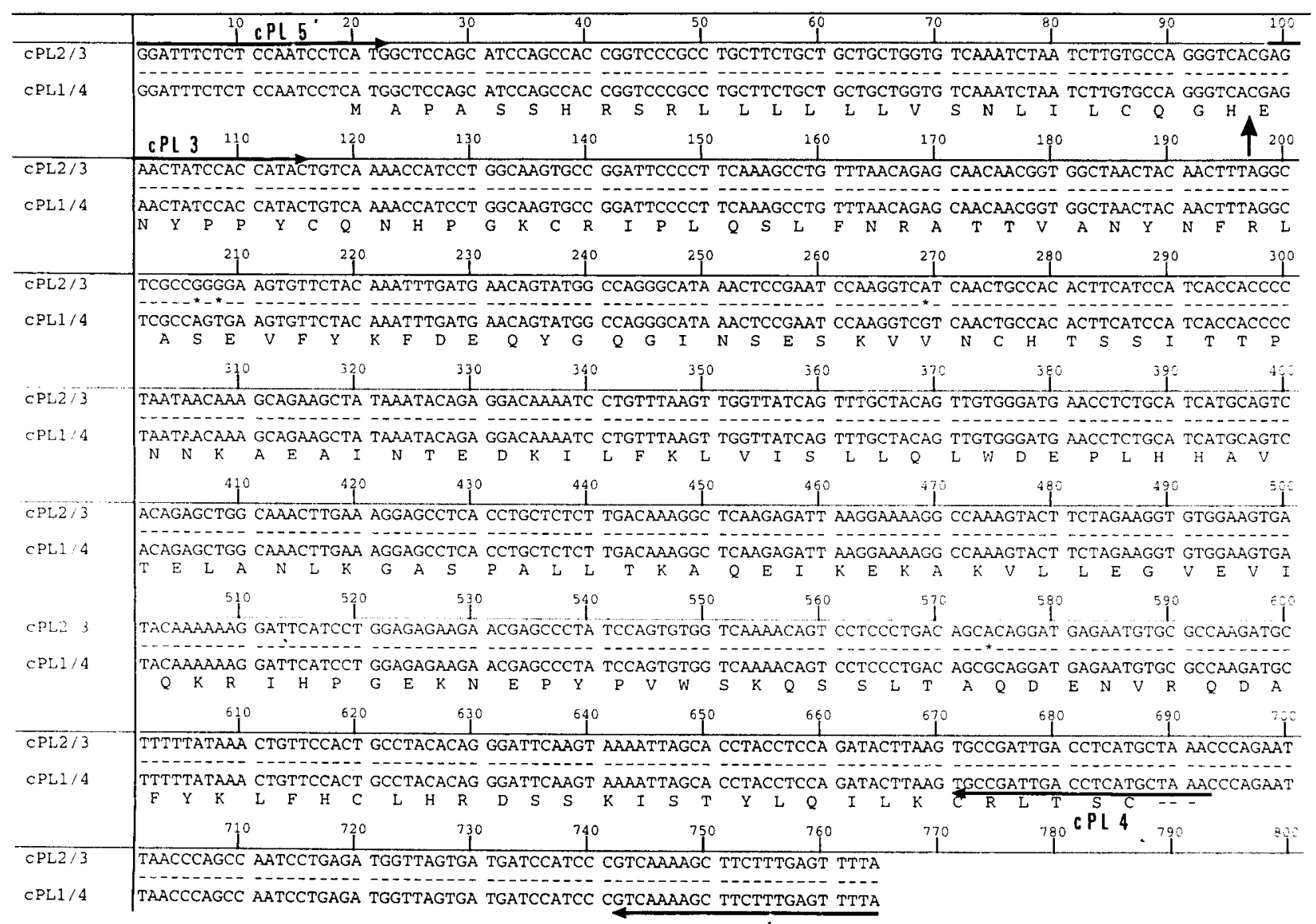

C P $3^{\circ}$

Figure 1 DNA sequence analysis revealed two bands of sequences illustrated by clones 1 and 4 and by clones 2 and 3 . The vertical arrow indicates the predicted first amino acid of the mature protein, and the horizontal arrows the respective primers (see text).

cPL was eluted from the column using a discontinuous $\mathrm{NaCl}$ gradient as described for the Q-Sepharose column, and was designated cPL-S.

\section{Determination of the amino-terminal sequence}

Automated Edman degradation technique was used to determine the amino-terminal protein sequence. Degradation was performed on an ABI Model 470A gas-phase sequencer (Foster City, CA, USA) using the standard sequencing cycle. The respective phenylthiohydantoin (PTH)-amino acid derivatives were identified by RPHPLC analyses, using an ABI Model 120A PTH analyzer fitted with a Brownlee $2 \cdot 1 \mathrm{~mm}$ i.d. PTH- $\mathrm{C}_{18}$ column.

\section{Determination of purity, monomer content and complex formation}

SDS-PAGE was carried out according to Laemmli (1970) using $12 \cdot 5 \%$ gel. Gels were stained with Coomassie
Brilliant Blue R. HPLC gel-filtration chromatography on a Superdex 75 HR 10/30 column was performed using $25 \mathrm{mM}$ Tris $-\mathrm{HCl}$ buffer, $\mathrm{pH} 8 \cdot 0$, containing $150 \mathrm{mM} \mathrm{NaCl}$ (TN buffer). Two hundred microliter aliquots of either Q-Sepharose or SP-Sepharose column-eluted fractions, freeze-dried samples dissolved in $\mathrm{H}_{2} \mathrm{O}$ or complexes between the soluble recombinant GHR- or PRLR-ECD and CPL, were analyzed using methods detailed previously (Bignon et al. 1994).

\section{Binding assays}

Hormones binding to the different ECDs and to rabbit mammary gland (MG) microsomal fraction were assayed as described previously (Sandowski et al. 1995, Sakal et al . 1997) using radiolabeled ${ }^{125} \mathrm{I}-\mathrm{oPL}$ as a ligand. Iodination of oPL was performed according to the protocol described by Gertler et al. (1984). 


\begin{tabular}{|c|c|c|c|c|c|c|c|c|}
\hline & 10 & 20 & 30 & 40 & 50 & 60 & 70 & 80 \\
\hline \multirow[t]{2}{*}{ ORL } & MAPASSHREH & QWTCNLVRGS & RLLLLLVVSN & LILCQGQAQH & PPYCRNQPGK & CQIPLQNLFD & RATTVANYNS & KLAGEMVNRE \\
\hline & $-------\infty * \star$ & $\varepsilon \notin \& \& \& \& \& \& \&-$ & ------*---- & $-\cdots---\star \star \star \star \star$ & $----^{\star}--_{-}-\cdots$ & $-\star----\star \star--\star$ & ---------* & $\star_{--*_{-}}$ \\
\hline \multirow[t]{2}{*}{ CPL } & MAPASSHR-- & ---------S & RLLLLLLVSN & LILCQGHENY & PPYCQNHPGK & CRIPLQSLEN & RATTVANYNF & RLASEVFYKF \\
\hline & --------\#\# & $\{\& \& \& \& \& \& \& \&-$ & \#------\#--- & -\#---- \#-\#- & \#---\#-\#--\# & -- - - - - - \# & ---\#--\#\#-\# & ---\#-\#-\#\#- \\
\hline \multirow[t]{2}{*}{ bPL } & MAPASSHRGH & QWICDLVRGS & CLLILLVVSN & ILLCQGAEDY & APYCKNQPGN & CRI PLQSLFE & RATLVASNNY & RLAREMENEF \\
\hline & 90 & 100 & 110 & 120 & 130 & 140 & 150 & 160 \\
\hline \multirow[t]{2}{*}{ OPI } & DEQYGQGINS & ESKVIN-CHT & SSITTPNNKA & EAINTEDKIL & FKLVISLLHS & WDEPLHHAVT & ELANSKGTSP & ALLTKAQEIK \\
\hline & ---------- & $----^{\star}-\alpha-\cdots$ & --------- & --------- & 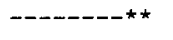 & - - - - - & $----^{\star}--\star--$ & --------- \\
\hline \multirow[t]{2}{*}{$\mathrm{CPL}$} & DEQYGQGINS & ESKVVN-CHT & SSITTPNNKA & EAINTEDKIL & FKLVISLLQL & WDEPLHHAVT & ELANLKGASP & ALLTKAQEIK \\
\hline & \#\#-\#-\#-\#-\# & \#--\#\#- --- & \#\#\#-------\# & \#-\#--- -\#\#- & \#\#-------\#\# & -.-----\#--- & --\#\#\#\#---- & \#\#-\#\#-\#--\# \\
\hline \multirow[t]{2}{*}{$\mathrm{bPL}$} & NKQFGEGKNF & TSKFINSCHT & EFMTT PNNKE & AAANTEDEAL & LRLVISLLHS & WDEPLHQAVT & ELLHRNGASP & DILARAKEIE \\
\hline & 170 & 180 & 190 & 200 & 210 & 220 & 230 & 237 \\
\hline \multirow[t]{2}{*}{ OPL } & EKAKVLVEGV & EVIQKRIHPG & EK-NEPYPVW & SEQSSLTSQD & ENVRQVAFYR & LFHCLHRDSS & KIYTYLRILK & CRLTSCET \\
\hline & ------*--- & $-\cdots-\infty-\infty$ & $--\&------$ & -*------*-- & $\ldots-\cdots-^{\star}-\cdots \star$ & $-----\cdots-$ & $--\star---\star---$ & $-\cdots$ \\
\hline \multirow[t]{2}{*}{ CPL } & EKAKVLLEGV & EVIQKRIHPG & EK-NEPYPVW & SKQSSLTAQD & ENVRQDAFYK & LFHCLHRDSS & KISTYLQILK & CRLTSC \\
\hline & \#-\#------- & -\#-----\#--- & $--\&-------$ & -\#\#-----\#- & -\#---ー\#---\# & \#---------- & -----\#\#\#-- & --\#-\#- \\
\hline bPL & DKTKVLLEGV & EMIQKRVHPG & EKKNEPYPVW & SEKSSLTADD & EDVRQTAFYR & MFHCLHRDSS & KISTYINLLK & CRFTPC \\
\hline
\end{tabular}

Figure 2 Comparison of the predicted full amino acid sequences (including signal peptides) of ovine, caprine and bovine placental lactogens. The differences between $\mathrm{CPL}$ and $\mathrm{OPL}$ are marked by ${ }^{*}$, and those between $\mathrm{CPL}$ and bPL are marked by \#. The \& sign indicates missing amino acids. The sequence of the mature protein starts at position 38 (oPL numbering).

\section{In vivo bioassays}

Three in vivo bioassays in which the signal was transduced through lactogenic receptors were performed: $\mathrm{Nb}_{2}-11 \mathrm{C}$ lymphoma cell proliferation bioassay (Gertler et al. 1985) and $\beta$-casein production in rabbit or ovine mammary gland acini culture (see below). Two aditional in vivo bioassays in which the signal was transduced through somatogenic receptors were based on the proliferation of FDC-P1 cells transfected with rabbit (clone FDC-P1RGHRB9) or human (clone FDC-P1-HGHRD11) GHRs (Rowlinson et al. 1995, 1996). Cells cultured in RPMI-1640 medium supplemented with 5\% horse serum and hGH $(100 \mathrm{ng} / \mathrm{ml})$ were washed and resuspended in RPMI-1640 medium supplemented with 5\% horse serum at a concentration of 150000 cells $/ \mathrm{ml}$ in $24-w e l l$ plates. Hormones were then added and the cells were grown for an additional period of $48 \mathrm{~h}$. Cell growth was determined by counting the cells with a Coulter counter (Coulter Electronics Inc., Hialeah, FL, USA) and the number of doublings was calculated as described previously (Gertler et al. 1985).

\section{Rabbit and sheep mammary gland acini culture}

Rabbit mammary gland was quickly recovered and kept on ice. The mammary gland was then cut and kept in Hank's balanced salt solution (HBSS) medium. Connective tissue and muscle were removed from each cut, and the remaining epithelial mammary tissue was then cut into small fragments with a scalpel and incubated for $2 \mathrm{~h}$ in HBSS medium containing $200 \mathrm{UI} / \mathrm{ml}$ collagenase IV, and $200 \mathrm{UI} / \mathrm{ml}$ hyaluronidase (Sigma Chemical Co.) and 2\% BSA at $37^{\circ} \mathrm{C}$. After digestion, the cellular suspension was filtered to remove the remaining connective and the undigested tissue. The acini suspension was decanted rapidly to eliminate the less heavy fibroblastic cells. The latter procedure was repeated five times. The acini suspension was then plated in 24-well plates in Dulbecco's modified Eagle's medium (DMEM)/HAM-F12 medium (Gibco BRL, Paisley, Strathclyde, UK) containing 2\% Ultroser SF (Biosepra, S.A., Villeneuve-la-Garenne, France), $2 \mathrm{mM}$ L-glutamine, $100 \mathrm{U} / \mathrm{ml}$ penicillin, $100 \mathrm{mg} / \mathrm{ml}$ streptomycin and $50 \mu \mathrm{g} / \mathrm{ml}$ gentamycin. After 4 days culture, the acini were incubated with different concentrations of oPRL or cPL for $48 \mathrm{~h}$. The $\beta$-casein secreted into the medium was determined by radioimmunoassay as described before (Jahn et al. 1987). The procedure for ovine mammary gland acini was similar to that described above, except that tissue digestion was performed in Earle's BSS medium with collagenase III (Gibco BRL) rather than collagenase IV. Two washings were performed for $20 \mathrm{~min}$ at $37^{\circ} \mathrm{C}$ in the presence of $0 \cdot 01 \%$ DNAse I, grade II (Boehringer, Mannheim, Germany) and, after a final wash to remove the enzyme, the cells were seeded and subsequently treated as described above. 


\section{Results}

Sequence analysis of the proteins encoded by the four cDNA clones

As described in Materials and Methods, the cPL cDNA was obtained by RT-PCR of goat placenta RNA. Sequence analysis revealed two kinds of sequences illustrated by clones 1 and 4 on the one hand, and by clones 2 and 3 on the other (Fig. 1). The four mismatches between these two sequences (G/A206, G/T208, G/A269 and A/G574) resulted in only two amino acid substitutions: S63 in clones 1 and 4 to G63; and V84 in clones 1 and 4 to I84 in clones 2 and 3. These two sequences could represent two alleles of the same gene with similar expression levels. After signal peptide removal, the cDNA encoded a 197 amino acid protein, which is two amino acids shorter than oPL. When aligned with oPL (Fig. 2), cPL exhibited $86 \%$ identity and $92 \%$ similarity at the protein level, with a shortened signal peptide of 11 amino acids for cPL (Fig. 2). The identity and similarity to bPL were $67 \%$ and $79 \%$ respectively, close to the values of $69 \%$ and $81 \%$ obtained in a respective comparison of oPL and bPL.

\section{Purification and characterization of E. coli-expressed cPL}

The protein contained in the inclusion bodies prepared from 2.51 induced cells was refolded in $4.5 \mathrm{M}$ urea as described in Materials and Methods. The refolded cPL was purified on a Q-Sepharose column by stepwise elution with increasing concentrations of $\mathrm{NaCl}$ (Fig. 3A). Aliquots from every sixth tube were analyzed for monomer content by gel filtration through a Superdex column. Fractions eluted with $0.05 \mathrm{M} \mathrm{NaCl}$ (see Fig. 3A, tubes 16-19) that contained monomeric cPL were pooled, dialyzed against $\mathrm{NaHCO}_{3}$ (at a 4:1 protein/salt ratio) and freeze-dried. This fraction (designated cPL-Q) contained pure monomer (Figs $3 \mathrm{~A}$ and $4 \mathrm{~B}$ ), whereas fractions eluted in $0.1 \mathrm{M}$ and $0.3 \mathrm{M} \mathrm{NaCl}$ contained increasing amounts of dimers and oligomers (not shown). Over $40 \%$ of the monomeric cPL was not absorbed by the Q-Sepharose column and was fully recovered in the breakthrough fraction (not shown). Therefore, the breakthrough fraction from the Q-Sepharose column was adjusted to $\mathrm{pH} 5 \cdot 0$ with $10 \%$ HAc and applied to a SP-Sepharose column $(1 \cdot 2 \times 8 \mathrm{~cm})$ previously equilibrated with $25 \mathrm{mM} \mathrm{NaAc}$ buffer, $\mathrm{pH} 5 \cdot 0$. Elution was carried out using a discontinuous $\mathrm{NaCl}$ gradient in the same buffer at a rate of $90 \mathrm{ml} / \mathrm{h}$, and $10 \mathrm{ml}$ fractions were collected (Fig. 3B). The pure monomeric cPL (as evidenced by gel filtration on a Superdex column) was eluted as a wide peak (second peak, fractions 26-31) with $0.35 \mathrm{M} \mathrm{NaCl}$. Caprine PL monomeric fractions from both columns (see Fig. 3 underlined) were dialyzed against $0 \cdot 1 \% \mathrm{NaHCO}_{3}$ and lyophilized. Inclusion bodies prepared from 2.51 fermentation culture yielded $\sim 35 \mathrm{mg}$ protein
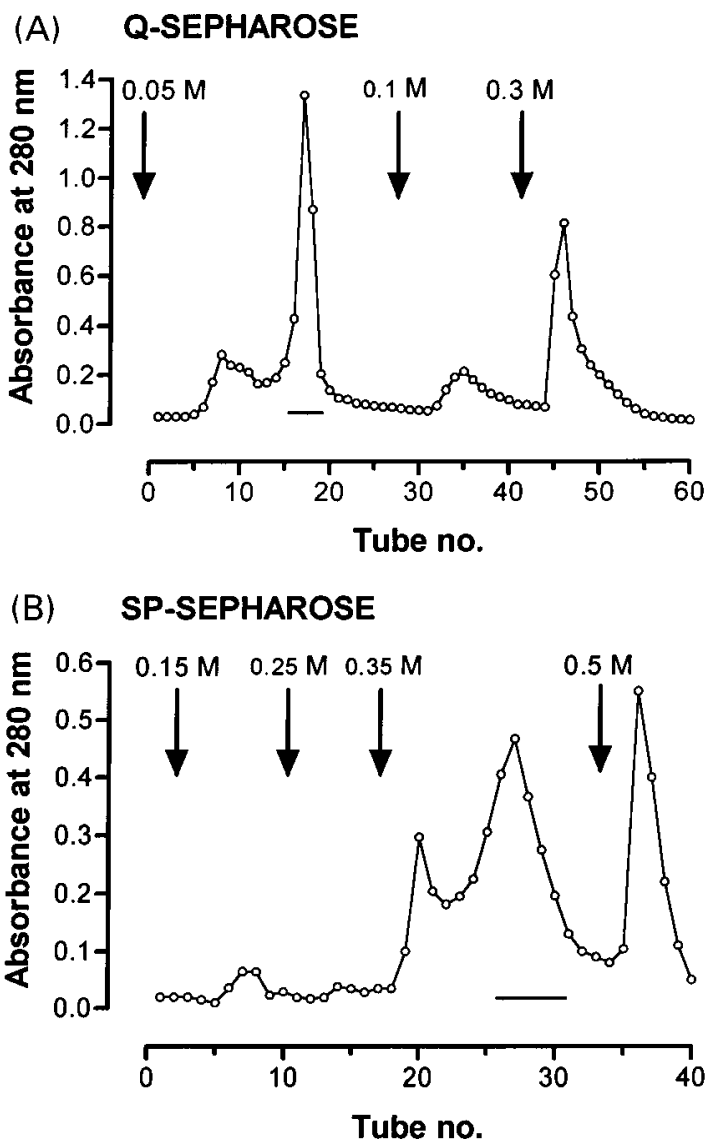

Figure 3 Purification of proteins extracted from inclusion bodies on Q-Sepharose and SP-Sepharose columns. (A) The Q-Sepharose column $(2.5 \times 7 \mathrm{~cm})$ was equilibrated with $10 \mathrm{mM}$ Tris- $\mathrm{HCl}$, pH $9 \cdot 0$, at $4{ }^{\circ} \mathrm{C}$. The refolded proteins were applied to the column at a rate of $120 \mathrm{ml} / \mathrm{h}$ and eluted with a discontinuous gradient of $\mathrm{NaCl}$ in the same buffer. (B) The non-absorbed fraction from the Q-Sepharose column was adjusted to $\mathrm{pH} 5.0$ by $10 \%$ HAc and applied to a SP-Sepharose column $(1.6 \times 8 \mathrm{~cm})$ pre-equilibrated with $0 \cdot 25 \mathrm{M} \mathrm{NaAc}$ buffer, $\mathrm{pH} 5 \cdot 0$. The column was then washed with a discontinuous gradient of $\mathrm{NaCl}$ in the same buffer. The flow rate was $120 \mathrm{ml} / \mathrm{h}$ in both columns and $10 \mathrm{ml}$ fractions were collected.

obtained from the Q-Sepharose column (cPL-Q) and $\sim 25 \mathrm{mg}$ protein obtained from the SP-Sepharose column (cPL-S). The freeze-dried hormone was stored at $-70{ }^{\circ} \mathrm{C}$ for at least 6 months, during which time neither dimers nor oligomers were formed. The purity of the monomeric cPL under non-denaturating conditions (Fig. 4B) was further confirmed by SDS-PAGE analysis in the presence or absence of reducing agents (Fig. 4A). Under reducing conditions both fractions yielded a single band with an apparent molecular mass of $\sim 23 \mathrm{kDa}$, close to the theoretical value of $22599 \mathrm{Da}$ (that includes an additional N-terminal Met) and similar to that of oPL. Under non-reducing conditions a single band was also observed. The mobility of this band was faster indicating globular 
$\mathbf{A}$
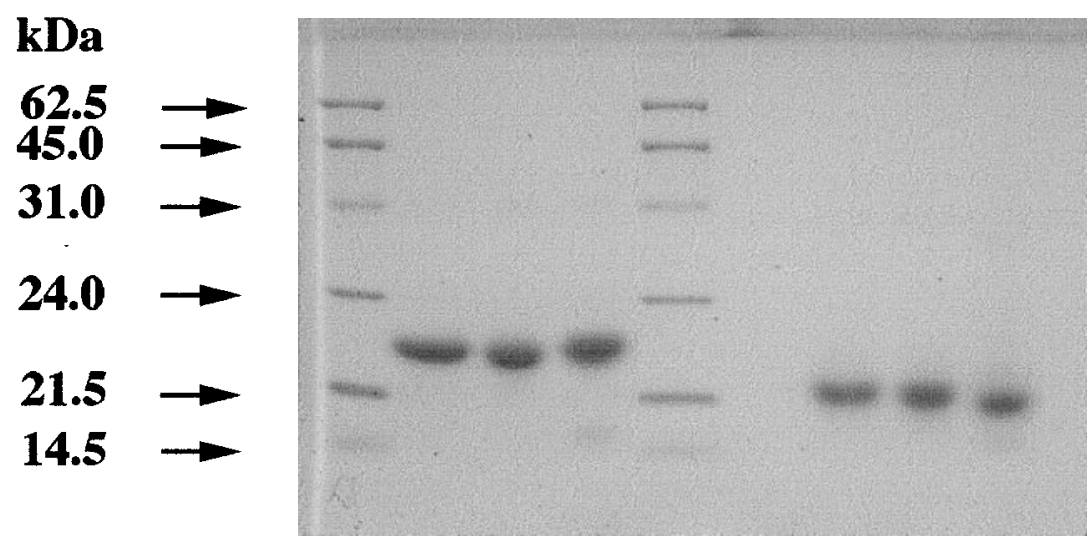

$\begin{array}{lll}1 & 2 & 3\end{array}$

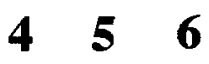

B

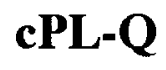

11.92

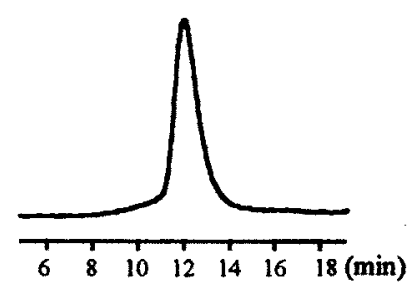

cPL-S

11.89

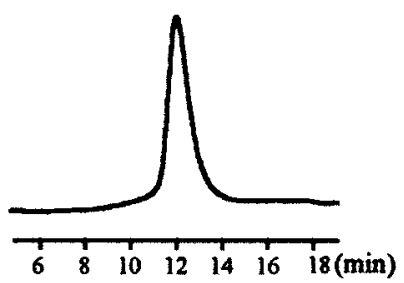

Figure 4 (A) SDS-PAGE of oPL, CPL-Q and CPL-S on 12.5\% SDS-polyacrylamide gel in the presence (lanes 1, 2, and 3) and in the absence (lanes 4, 5 and 6) of $\beta$-mercaptoethanol. The gel was stained with Coomassie Brilliant Blue R. Molecular mass markers are shown on the left. (B) Determination of the CPL-Q and CPL-S monomer content by gel-filtration chromatography on a Superdex 75 HR 10/30 column. Protein content was monitored by absorbance at $280 \mathrm{~nm}$ using a Merck-Hitachi D-2000 integrator. The column was developed at $1 \mathrm{ml} / \mathrm{min}$ with $25 \mathrm{mM}$ Tris- $\mathrm{HCl}$ buffer, $\mathrm{pH} 8 \cdot 0$, containing $150 \mathrm{mM} \mathrm{NaCl}$. The numbers above the peak show the retention time. The retention times of bovine albumin $(67 \mathrm{kDa})$ and oPL $(23 \mathrm{kDa})$ were $9 \cdot 45$ and $11 \cdot 88$ min respectively.

structure. Amino-terminal analysis of the first 7 amino acids yielded the expected sequence, namely Met-GluAsn-Tyr-Pro-Pro-Tyr for both cPL-Q and cPL-S. The respective yields (in picomols) were for cPL-Q: 163, 135, $115,153,141,85,99$, and for cPL-S: 157, 145, 118, 147, 112, 98 and 116.

\section{Binding experiments}

Radiolabeled oPL was chosen as a ligand for the binding and competition experiments that were conducted with oPL, cPL-Q and cPL-S (Fig. 5 and Table 1). The results were analyzed by PRIZMA software (GraphPad Prism 

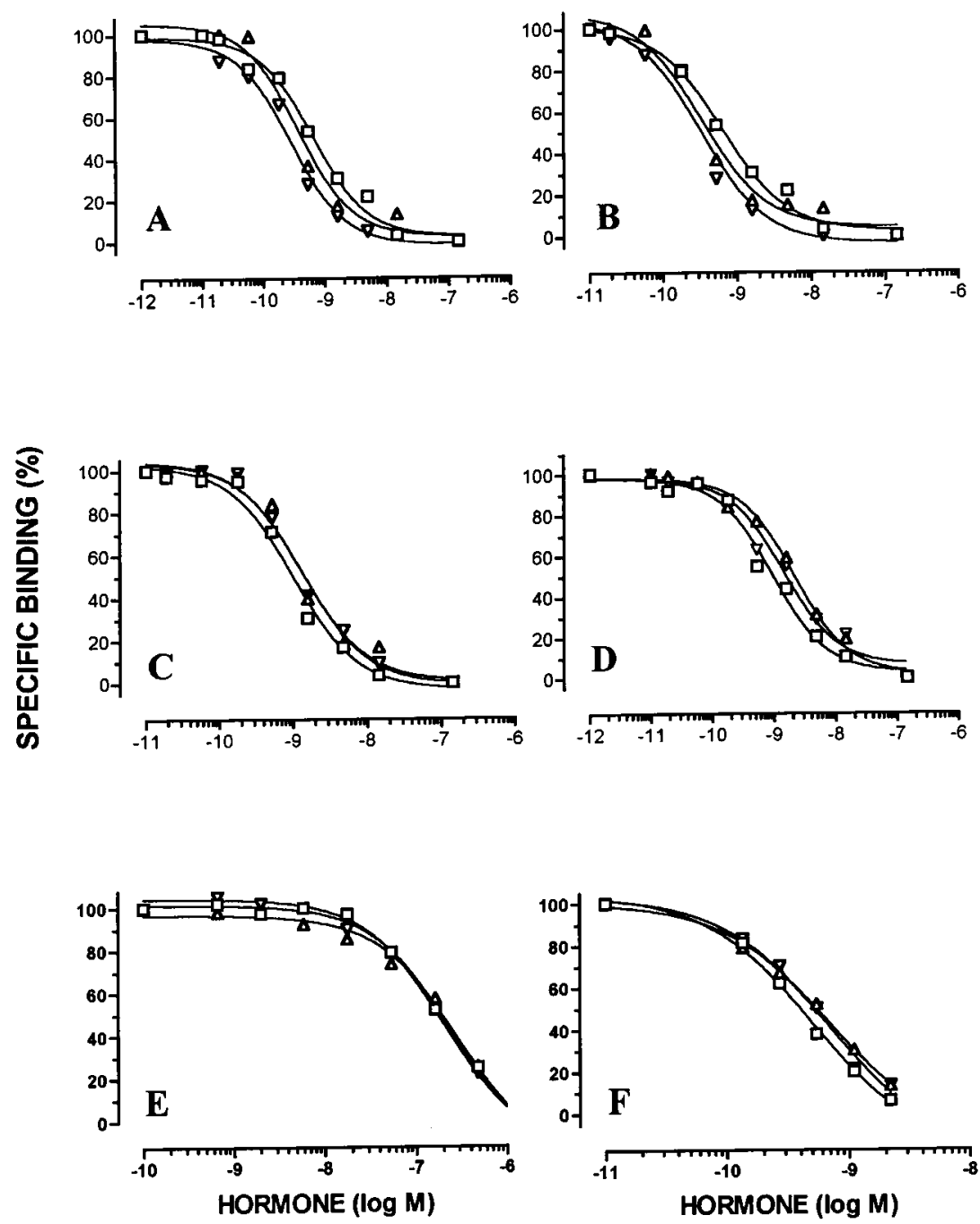

Figure 5 Competition of unlabeled oPL $(\square)$, cPL-Q $(\triangle)$ and $\mathrm{CPL}-\mathrm{S}(\nabla)$ with ${ }^{125} \mathrm{I}$-oPL for binding to (A) hGHR-ECD, (B) rbGHR-ECD, (C) rbPRLR-ECD, (D) rPRLR-ECD, (E) bPRLR$\mathrm{ECD}$ and $(\mathrm{F})$ rbMG. The specific binding was $27 \%$ in $(\mathrm{A}), 22 \%$ in $(\mathrm{B}), 19 \%$ in $(\mathrm{C}), 21 \%$ in (D), $15 \%$ in (E) and $35 \%$ in (F). Full lines were calculated using the PRIZMA curve-fitting program.

Version $2 \cdot 0$ 1994) according to a non-linear regression one-site competition dose-response curve. In all analyses the degree of the non-linear correlation was very high $\left(\mathrm{R}^{2}>0 \cdot 97\right)$ and higher than for the two-site competition curves. Though $\mathrm{IC}_{50}$ values for oPL, cPL-Q and cPL-S were similar in general (Fig. 5 and Table 1), both cPL-Q and cPL-S (as compared with oPL) were slightly less effective competitors for rbPRLR-ECD, rPRLR-ECD and $\mathrm{rbMG}$ microsomal fraction and slightly more effective for rbGHR-ECD and hGHR-ECD. As shown before for oPL (Sakal et al. 1997) and for bPL (Gertler et al. 1996), the $\mathrm{IC}_{50}$ values for binding to bPRLR-ECD were higher than for other receptors and the specific binding of the ${ }^{125} \mathrm{I}-\mathrm{oPL}$ was lower. This was a result of lower affinity and subsequently the need to use a larger amount of bPRLR-ECD to achieve specific binding.

\section{Gel-filtration experiments}

The stoichiometry of the interactions between purified rbPRLR-ECD, rPRLR-ECD, bPRLR-ECD, hGHRECD, rbGHR-ECD and cPL-Q was studied by preparing the respective complexes at increasing ECD:hormone ratios, while maintaining a constant concentration $(1.6 \mu \mathrm{M})$ of the latter. Caprine PL-Q formed a detectable 1:2 complex with rbGHR-ECD and hGHR-ECD, whereas with bPRLR-ECD only a 1:1 complex was observed (Fig. 6). These conclusions were based on a 
Table 1 The $\mathrm{IC}_{50}$ values of oPL, CPL-Q and CPL-S calculated from the binding experiments presented in Fig. 5 .

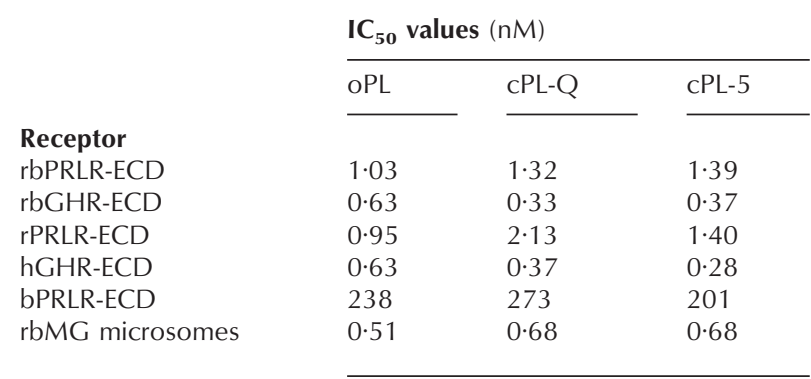

comparison of the sizes of the complex peaks and their retention times. The complexes with rbPRLR-ECD and rPRLR-ECD showed 1:2 stoichiometry as indicated by the retention times of $9.89-9.95$ and $10.02-10.07 \mathrm{~min}$ respectively compared with a retention time of $10 \cdot 88 \mathrm{~min}$ for the complex with bPRLR-ECD. The appearance of the excess of ECDs when the hormone was preincubated with two equivalents of PRLR-ECD indicated, however, that the complex was not stable and dissociated in the

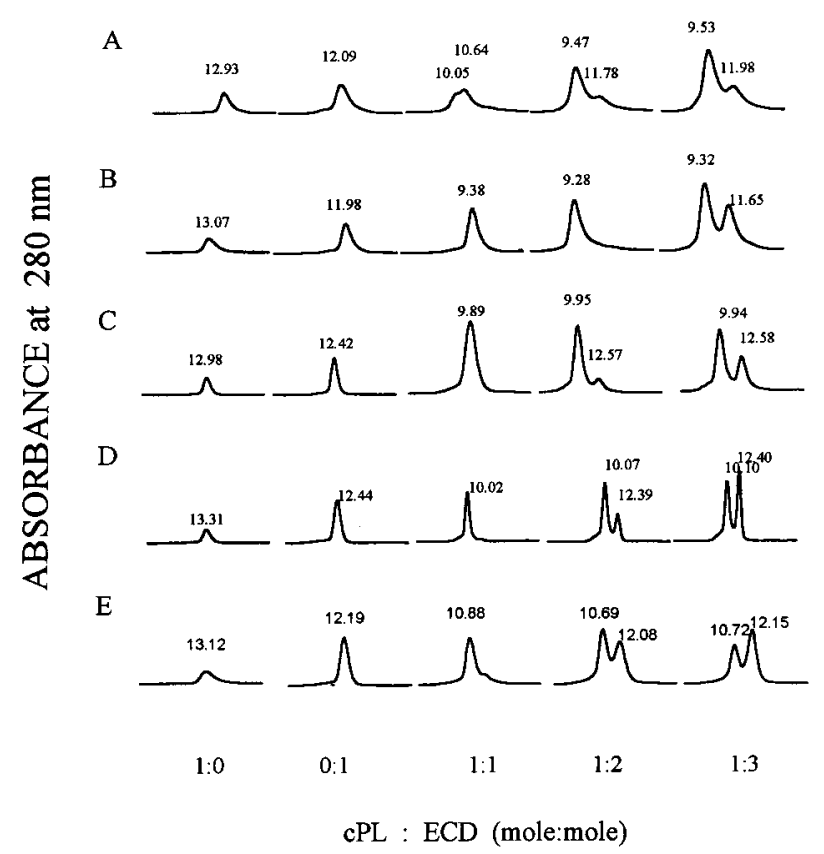

Figure 6 Gel filtration of $c P L-Q$ complexes with (A) hGHRECD, (B) rbGHR-ECD, (C) rbPRLR-ECD, (D) rPRLR-ECD and (E) bPRLR-ECD on a Superdex 75 HR 10/30 column. Complex formation was carried out during 20 to $30 \mathrm{~min}$ incubation at room temperature in TN buffer using various ECD:CPL ratios. The initial hormone concentration was constant $(1 \cdot 6 \mu \mathrm{M})$. Aliquots $(200 \mu \mathrm{l})$ of the incubation mixture were applied to the column, preequilibrated with the same buffer. Complex formation was monitored by absorbance at $280 \mathrm{~nm}$. The column was developed at $1 \mathrm{ml} / \mathrm{min}$. Each experiment was conducted at least three times. course of gel filtration. Similar experiments performed with cPL-S showed the same results (not shown).

\section{Biological activity in vitro}

Lactogenic activity of cPL-Q and cPL-S in a $\mathrm{Nb}_{2}$ cell proliferation bioassay was as potent as that of oPL (Fig. 7A) and the respective $\mathrm{EC}_{50}$ values were $1.4 \times 10^{-12} \mathrm{M}$,
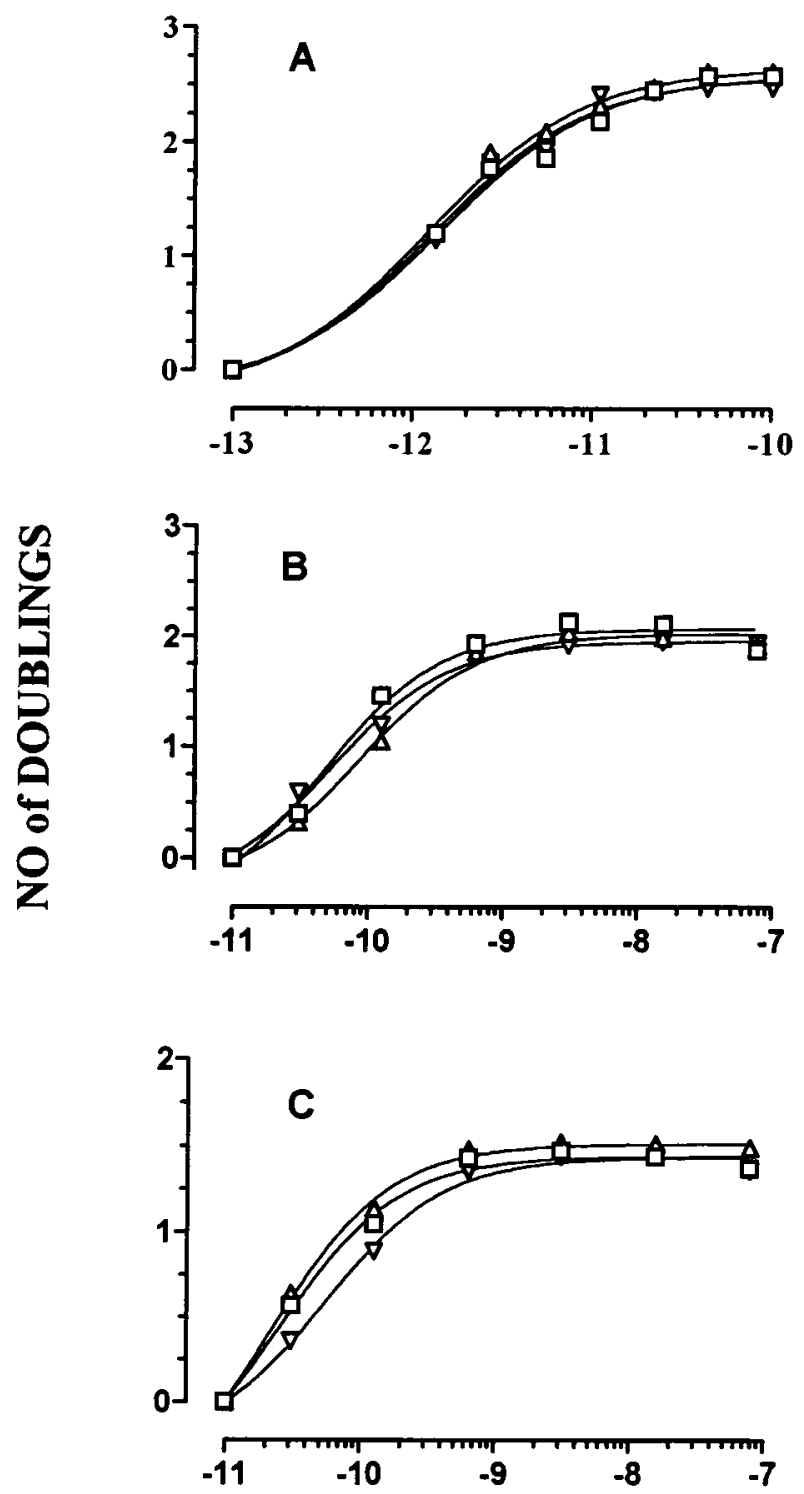

HORMONE $(\log M)$

Figure 7 Effect of oPL $(\square)$, cPL-Q $(\triangle)$ and cPL-S $(\nabla)$ on the proliferation of (A) $\mathrm{Nb}_{2}-11 \mathrm{C}$ lymphoma cells, (B) FDC-P1hGHR9D11 cells, and (C) FDC-P1-rbGHR3B9 cells. Number of doublings was calculated as described previously (Gertler et al. 1985). 

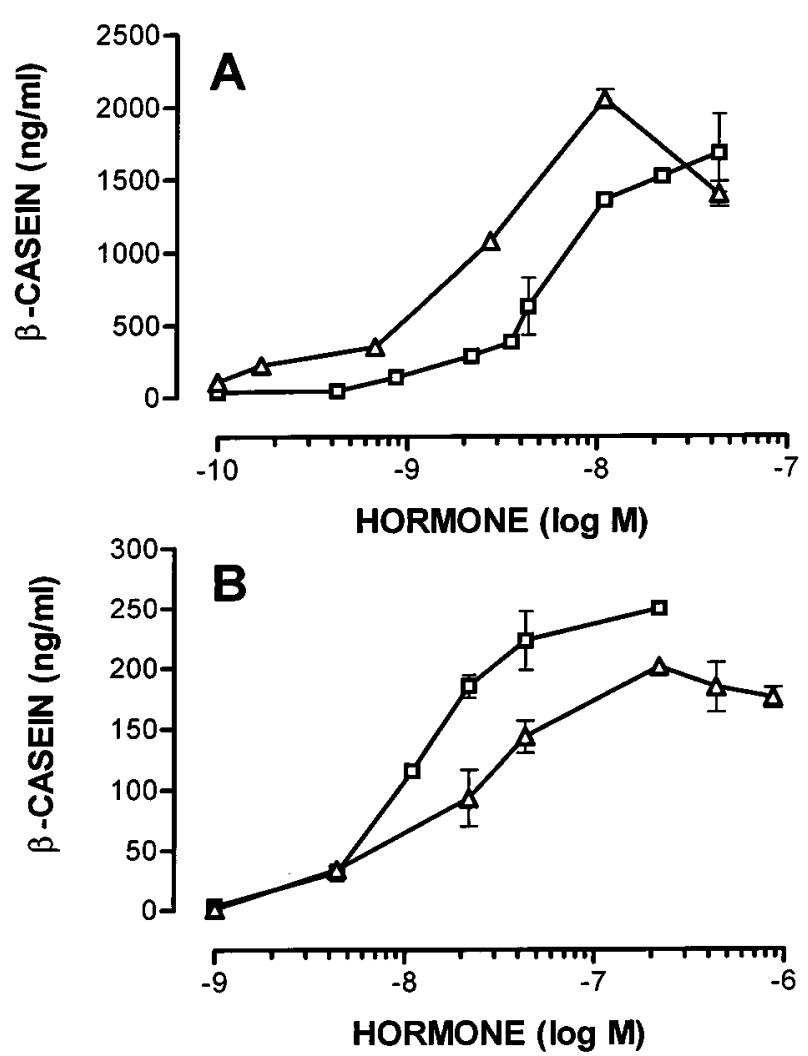

Figure 8 Effect of $c P L-Q(\triangle)$ and oPRL $(\square)$ on $\beta$-casein production in $(\mathrm{A})$ rabbit and $(\mathrm{B})$ ovine mammary gland acini culture. The results are means \pm S.D. of two replicates.

$1.2 \times 10^{-12} \mathrm{M}$ and $1.3 \times 10^{-12} \mathrm{M}$. Caprine PL stimulated $\beta$-casein synthesis in rabbit (Fig. 8A) and in sheep acini culture (Fig. 8B). In rabbit culture, the activity of cPL-Q was slightly higher than that of oPRL, $\left(\mathrm{EC}_{50}=2 \times 10^{-9}\right.$ vs $\left.6 \times 10^{-9} \mathrm{M}\right)$, whereas in sheep culture it was slightly lower $\left(\mathrm{EC}_{50} \sim 30 \times 10^{-9}\right.$ vs $\left.10 \times 10^{-9} \mathrm{M}\right)$. In both cases the concentration of $\mathrm{cPL}$ required for half-maximal activity were two to three orders of magnitude higher than in a $\mathrm{Nb}_{2}$ cell proliferation bioassay. Somatogenic activity of $\mathrm{CPL}-\mathrm{Q}$ and $\mathrm{cPL}-\mathrm{S}$ was almost identical to that of oPL in two heterologous bioassays in FDC-P1 cells transfected with either hGHRs (Fig. 7B) or rbGHRs (Fig. 7C). The respective $\mathrm{EC}_{50}$ values for cPL-Q, cPL-S and oPL calculated from Fig. 7B were $4.7 \times 10^{-11} \mathrm{M}, 8.7 \times 10^{-11} \mathrm{M}$ and $6.4 \times 10^{-11} \mathrm{M}$ and from Fig. $7 \mathrm{C} 2.5 \times 10^{-11} \mathrm{M}, 2 \cdot 1 \times 10^{-11} \mathrm{M}$ and $5.5 \times 10^{-11} \mathrm{M}$. These values were 20 - to 50 -fold higher compared with those observed in $\mathrm{Nb}_{2}$ cells.

\section{Discussion}

Caprine PL was cloned in and expressed in E. coli BL21 cells. Two electrophoretically pure cPL fractions (cPL-Q and cPL-S) composed of over $98 \%$ of monomer and a small quantity of dimers were obtained. Since the N-terminal analysis of both fractions was identical we assume that they differ by a small charge change. The more acidic fraction, cPL-Q, was probably created by deamination of one or more glutamine residues during the refolding procedure at a high $\mathrm{pH}$. As shown above, this difference had no effect on the biological activity, which was equal to that of oPL, the biological activity of which has been documented previously (Sakal et al. 1997). These results prompt us to conclude that both cPL fractions were properly refolded. There was no difference in the ability of the cPL fractions to bind to several types of soluble or membrane-embedded lactogenic and somatogenic receptors. Their ability to form complexes with different soluble GHR- or PRLRECDs was also identical and in general very similar to that of oPL.

Cloning of cPL enabled us to compare its primary structure to that of other ruminant placental lactogens. The data clearly show that the similarity between $\mathrm{CPL}$ and oPL exceeds the one between bPL and oPL or cPL. In contrast to these, the similarity between the corresponding GHs and PRLs in the three ruminant species is much greater (Byatt et al. 1992). It has been suggested that this finding may be indicative of different physiological roles that PLs may play in the three species (Byatt et al. 1992). So far, this point has not been proven. We have at present elucidated the three-dimensional structure of the 1:2 complex between oPL and the rPRLR-ECD, and have been able to identify the 25 residues of oPL that participate in site I of the hormone and the 24 residues that participate in site II (Christinger et al. 1998). Interestingly, the extent of identity (and similarity) between oPL and cPL in these residues (72\% and $80 \%$ for site I and $79 \%$ and $89 \%$ for site II) was not higher than the overall identity. The equal potency of both hormones to induce a biological effect mediated through rPRLR (see Fig. 7A) suggests that differences in the primary structure may not necessarily be indicative of different biological activities, although the final conclusion requires results using homologous models.

A particular feature observed previously for bPL and oPL (Tchelet et al. 1995, Gertler et al. 1996, Sakal et al. 1997), namely the low affinity for binding for the soluble bPRLR-ECD and the inability to show an apparent 1:2 complex, was also observed in the case of cPL. A comparison of the parameters of binding and of interaction between cPL and rbPRLR-ECD or rbMG microsomal fraction to that of bPRLR-ECD (see Figs 5 and 6), shows the apparent affinity for rabbit-derived proteins to be 200 to 400 times higher and this probably explains the compromised ability to form an apparent 1:2 complex with bPRLR-ECD. Despite this, the concentration of cPL required for half-maximal simulation of $\beta$-casein synthesis in rabbit MG acini was only 15-fold lower $\left(\mathrm{EC}_{50}=2 \times 10^{-9} \mathrm{M}\right)$ than in the corresponding ovine culture $\left(E_{50}=30 \times 10^{-9} \mathrm{M}\right)$. These results raise the 
question as to the correlation between the binding of $\mathrm{cPL}$ to rabbit and ovine lactogenic receptors and the biological activity transduced as a result of this interaction. A possible explanation for this apparent discrepancy may be our recent suggestion that transient dimerization of PRLRs, lasting a few seconds or less, is sufficient to elicit a full biological response (Gertler et al. 1996). This suggestion is supported by the finding that receptor-associated $\mathrm{JAK}_{2}$ or other kinases are instantly activated by mutual transphosphorylation, subsequent to homodimerization of the receptor, forming docking sites for other downstream proteins (Goffin \& Kelly 1997). Once this happens, the existence of the receptor homodimer is no longer required for signal transduction. Therefore, the shorter persistence of the receptor homodimer in ovine MG compared with rabbit MG does not cause any major biological disadvantage, and despite the 200- to 400-fold differences in the affinity constants, the difference in dose-response of the biological signal ( $\beta$-casein synthesis) in both tissues is much less (see Fig. 8). Thus, the classical pharmacological theory that the biological activity is directly related to receptor occupancy does not possibly apply to cytokine receptors such as PRLR in which transient homodimerization is sufficient to initiate the transduction of the biological signal.

\section{Acknowledgements}

The authors thank the National Hormone and Pituitary Program (Bethesda, MD, USA) for ovine prolactin.

\section{References}

Anthony RV, Liang R, Kayl EP \& Pratt SL 1995 The growth hormone/prolactin gene family in ruminant placentae. Journal of Reproduction and Fertility (Suppl) 49 83-95.

Bignon Ch, Sakal E, Belair L, Chapnik-Cohen N, Djiane J \& Gertler A 1994 Preparation of recombinant extracellular domain of rabbit prolactin receptor expressed in Escherichia coli and its interaction with lactogenic hormones. Journal of Biological Chemistry 269 $3318-3324$.

Byatt JC, Wallace CR, Bremel RD, Collier RJ \& Bolt DJ 1987 The concentration of bovine placental lactogen and the incidence of different forms in fetal cotyledons and in fetal serum. Domestic Animal Endocrinology 4 231-241.

Byatt JC, Welply JK, Leimgruber RM \& Collier RJ 1990 Characterization of glycosylated bovine placental lactogen and the effect of enzymatic deglycosylation on receptor binding and biological activity. Endocrinology 127 1041-1049.

Byatt JC, Warren WC, Eppard PJ, Staten NR, Krivi GG \& Collier RJ 1992 Ruminant placental lactogens: structure and function. Journal of Animal Sciences 70 2911-2923.

Colosi P, Thordarson G, Hellmiss R, Singh K, Forsyth IA, Gluckman PD \& Wood WI 1989 Cloning and expression of ovine placental lactogen. Molecular Endocrinology 3 1462-1469.

Christinger HW, Elkins PA, Sandowski Y, Sakal E, Gertler A, Kossiakoff AA \& de Vos AM 1998 Crystallization of ovine placental lactogen in a 1:2 complex with the extracellular domain of the rat prolactin receptor. Acta Crystallographica (In Press).
Forsyth IA 1986 Variations among species in the endocrine control of mammary growth and function: the roles of prolactin, growth hormone and placental lactogen. Journal of Dairy Science 69 866-878.

Freemark M \& Comer M 1989 Purification of a distinct placental lactogen receptor, a new member of growth hormone/prolactin receptor family. Journal of Clinical Investigations 83 883-889.

Galosi SS, Gertler A, Elberg G \& Laird DM 1991 Distinct placental and prolactin (lactogen) receptors in bovine endometrium. Molecular and Cellular Endocrinology 78 229-236.

Gertler A, Ashkenazi A \& Madar Z 1984 Binding sites of human growth hormone and ovine and bovine prolactins in the mammary gland and the liver of lactating dairy cow. Molecular and Cellular Endocrinology 34 51-57.

Gertler A, Walker A \& Friesen HG 1985 Enhancement of human growth hormone stimulated mitogenesis of $\mathrm{Nb} 2$ node lymphoma cells by tetradecanoyl-phorbol-13-acetate (TPA). Endocrinology 116 1636-1644.

Gertler A, Hauser SD, Sakal E, Vashdi D, Staten NR, Freeman JJ \& Krivi GG 1992 Preparation, purification and determination of the biological activities of twelve N-terminus truncated recombinant analogues of bovine placental lactogen. Journal of Biological Chemistry 271 12655-12659.

Gertler A, Grosclaude J \& Djiane J 1996 Affinity and stoichiometry of interaction between extracellular domains (ECDs) of prolactin receptor (PRLR) from three species and various lactogenic hormones. Journal of Biological Chemistry 271 24482-24491.

Goffin V \& Kelly PA 1997 The prolactin/growth hormone family: structure/function relationship. Journal of Mammary Gland Biology and Neoplasia 2 7-17.

Hulet CV \& Shelton M 1980 Sheep and goat. In Reproduction of Farm Animals, pp 346-354. Ed ESE Hafez. Philadelphia: Lea \& Febinger.

Jahn G, Dusanter-Fourt I, Kelly PA, Houdebine LM \& Djiane J 1987 Measurement by radioimmunoassay of casein content in rabbit mammary gland during pregnancy and after prolactin stimulation in organ culture. Procceedings of the Society for Experimental Biology and Medicine 184 19-23.

Laemmli UK 1970 Cleavage of structure proteins during assembly of the head of bacteriophage T4. Nature 227 680-685.

Rowlinson SW, Barnard R, Bastiras S, Robins AJ, Brinkworth R \& Waters MJ 1995 A growth hormone agonist produced by targeted mutagenesis at binding site 1. Journal of Biological Chemistry $\mathbf{2 7 0}$ 16833-16839.

Rowlinson SW, Waters MJ, Lewis, UJ \& Barnard R 1996 Human growth hormone fragments 1-43 and 44-193: in vitro somatogenic activity and receptor binding characteristics in human and non-primate systems. Endocrinology 137 90-95.

Sakal E, Bignon Ch, Kantor A, Leibovitch H, Shamay A, Djiane J \& Gertler A 1997 Large-scale preparation of recombinant ovine placental lactogen. Journal of Endocrinology 152 317-327.

Sandowski Y, Nagano M, Bignon C, Djiane J, Kelly PA \& Gertler A 1995 Recombinant extracellular domain of rat prolactin receptor interacts with different affinity and stoichiometry with various lactogenic hormones. Molecular and Cellular Endocrinology 115 1-11.

Shamay A, Pines M, Waksman M \& Gertler A 1990 Proliferation of bovine mammary epithelial cells in vitro is modulated by G-proteins. Molecular and Cellular Endocrinology 69 217-226.

Tchelet A, Staten NR, Creely DP, Krivi GG \& Gertler A 1995 Extracellular domain of prolactin receptor from bovine mammary gland: expression in Escherichia coli, purification and characterization of its interaction with lactogenic hormones. Journal of Endocrinology 144 393-403.

Wallis M 1992 The expanding growth hormone/prolactin family. Journal of Molecular Endocrinology 9 185-188.

Received 3 April 1998

Accepted 27 July 1998 